\title{
3um E̋eleit
}

\begin{abstract}
$D^{2}$ ie Ridutlinien der fauftausgabe, die nunmehr an die Gffentlidfeit tritt, find in dem Bude des Derfafiers „3u Boethes fauft" (Berlin und Eeipjig 1919, Dereini=

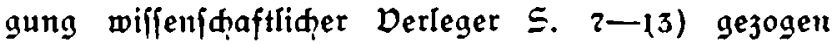
worden. Danad geht jedem Zlfte eine Einleitung voraus, in der die Zrbeit des Didters an den Ulfte, die anftreten= den perfonen, die brtlidfeiten der Sjenen, der Bang dcr Gandlung, endlid, Einzeltheiten bejprod,en werden. die für das Derftändnis des Zfftes von befonderer $\mathfrak{B}_{e}$ s deutung find. İn folḑen Einzelabhandlungen enthält

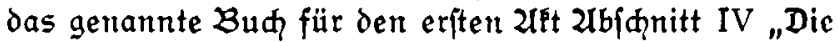
Mummeniananj", VI "Die Imiitter"; für den zweiten V

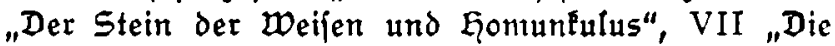
Flaffif hue Walpurgisnadqu; für den dritten III "Das Plaffifdy=romantifhe Jwilhenlpiel Eelena", VIII "Die Ertliḑeit dẹr fauftburg in der Gelena", IX "Das Bachas nal in der helena"; für den fünften $X$ "Ulm faujts $\mathfrak{U}_{n}=$ fterblidges". Die Kenntnis diejer Zbhandlungen (bejeid, net 3 Bf I, II uiw.) ift für den Benutzer des Kommentars nidḩt unumgängliḑ notwendig, wohl aber wänjhenswert, da fawierigete fragen darin auf breiterer Brundlage
\end{abstract}




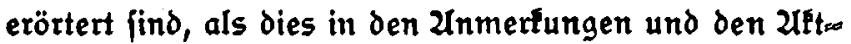
einleitungen möglid if.

Bewufit if der Derfaffer Feiner fprahlihen oder fad liḑen Sḩwierigleit aus dem Wege gegangen, unbewuf̈t waḩrfąeinliă gar man丸̧er. Bei einem werfe wie dem fauft darf ein einjelner trob ehrrliąer Bemühung und

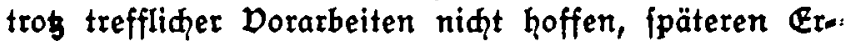
Jlärem eine nur magere Zaąleje übrig gelaffen ju haben. Dem Derfaffer felbfi ergaben fia bei jeder neuen Duraarbeitung immer mieder neue und niat felten entfaeibende Gefihtspunte für die Etflärung.

Zugrunde liegt der neuen Uusgabe der von Eria Shmidt im 14. und 15. Bande ber grofien Weimarer Uusgabe (w2U) geftaltete Cert (im wefentlidien gleidy lautend mit dem im 13. und 14. Bande der Cottająen Jubiläumsausgabe - $\mathfrak{J}-$ ), niqut als eine für alle

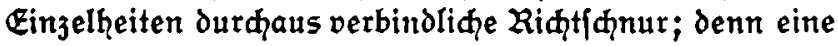
folde if er niat und lann er bei der verwidelten be. faidhte des faupttertes auh niḩt fein, doh immerhin als das zurzeit verläßlidffe fundament. Philologifher Uf́ribie bietet die feftifellung des fauftextes ein dornens volles und Paum fehr ergiebiges $\mathcal{Z}$ rbeitsfeld, das aber von einer rüftigen und gerüfteten $\mathfrak{U}$ rbeitsfraft doఢ noक einmal beftellt werden muß̧. Es jelbft $\mathfrak{z}$ tun, verbot dem Derfaffer die dringendere Zưfgabe der Erflärung. Er hat fia deshalb nur geringe 2 brweiđungen von $\mathbb{E}$. Samiots Cert geftattet. Sie betreffen in der Gauptiahe izenifąe Bemerfungen, die fortzulaffen waren, foweit fie in der Weimarer Gaupthand harift fehlen; die Sqreibung antifer ZTamen, über deren Uusfprahe wir heute genauer als

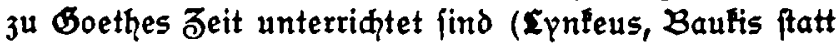
Epnceus, Baucis); endlid die Jnterpuntion, die Boethe

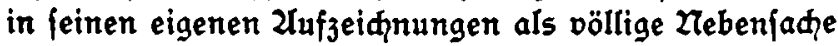
behandelt, und für die felbft die dura viele Gände ge 
gegangene Gandianrift niaht immet als majgebend gelten tann *).

Innerḩalb der einzelnen ulte ift, abweidend von der Gandjhrift, $\mathfrak{j}^{\mathfrak{u}}$ bequemerer aberfidt eine Sheidung in Sjenen und Uuftritte duragefühnt morden, die jedodGoe. thes Cett oöllig unberührt läf̧t. In jeder Szene werden die Derfe für fiq gezählt, doq ift die Dersłahl der Weimarer Zusgabe, in der beide Ceile des fauftramas als ein Banjes duragezählt merden, auf jeder Seite angegeben.

Dolfstümlid im landläufigen Sinne wird Boethes fauft, namentlia im 3weiten Ceile, nie werden. Zber einen grö̈eren Eejerfreis als bisher Fann und wird er finden. Dafür bürgt dem Derfaffer der Erfolg feiner langjährigen Dorträge, die um fo meḩr Ğörer und freunde fid gemannen, je eingehender fie maren. $\mathfrak{A u}_{\text {a }}$

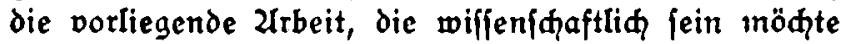
oḥne Dunfelheit und verfändlia ohne flađheit, foll daju mitḩelfen, das deutiąe Kationaldrama in Kreife $\mathfrak{u}$ tragen, die aus furht por feinen Shwierigleiten fid ihm bisher verialofien. Denn die Sdimierigleiten Iaffen fid heben, und die darauf gemendete mühe belohnt fia durd den Genub eines Kunftwerts, wie es anjaqualider und gedanfentiefer die weltliteratur niaht befigt.

In Jahresfrift etwa foll der erfte Ceil des fauf er fąeinen, in ähnliquer weife bearbeitet wie ber nor liegende. Es wird feinem Kommentar niđht faqden, daß̧ er nad dem des zweiten Ceiles niedergefąrieben worden ift, und dem Derftänonis der Diđtung nidht, wenn der sefer, nit dem jweiten Ceile vertraut, an den erften herantritt. Die Beføllofienheit des Jugend.

*) Auber der weimarer lund Cottajhen ift aud die Gems pellde Ausgabe der werte Goethes 34 Rate gezogen worben, bie in Derbindung mit anderm beleb̧rten Karl flt im Derlage pon Bong u. Co. neu herausgegeben b̧at (BA). 
wertes wird fiđ nur um fo ftärfer geltend mađen, feine eigentümliquen Dorzäge werden in der fatten Beleuditung

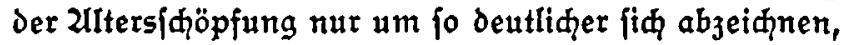
und 2abend und Morgen eines fonnigen Didterlebens werden fiф die Gand rei丸en, wie im ewig hellen Sande ber homerifąen säftrygonen der von der weide heintkehrende Girt den zur Weide ausjiehenden begrübt.

Berlin, Pfingften 1921

\section{0olf Trenbelenburg}

